\title{
The Effect of Using Audio Files on Improving Listening Comprehension
}

\author{
Kamran Mohamadkhani \\ Department of Higher Education Administration, School of Management and Economics, \\ Science and Research Branch, Islamic Azad University (IAU), Tehran, Iran, \\ k.kamran@srbiau.ac.ir
}

Ebrahim Nazari Farokhi

Department of Information Technology Management, School of Management and Economics, Science and Research Branch, Islamic Azad University (IAU), Tehran, Iran, E60_itmgtn@yahoo.com

Hossein Nazari Farokhi

English Department, Faculty of Humanities, IK International University, Qazvin, Iran, H.nazarifarokhi@gmail.com

Accepted: December 17, 2012 Published: January 31, 2013

Doi:10.5296/ijld.v3i1.3187

URL: http://dx.doi.org/10.5296/ijld.v3i1.3187

\begin{abstract}
:
This article points out the results of the study investigating the effect of using audio files on improving listening comprehension of high school students in Khorramabad -Iran-. For the purpose of the topic, two groups of students consisting of thirty four were randomly selected and were divided into two groups of seventeen. Research method was quasi-experimental. Although some native audio files were presented for the experimental group, both experimental and control group taught in the same style. According to the results of post listening test and the related comparisons, findings showed that using audio files had positive meaningful effect on improving listening comprehension.
\end{abstract}

Key Words: $\quad$ Listening Comprehension, Audio Files, Listeners, Multimedia

\section{Introduction:}

Technology may at first entered to the language classroom in the form of the language laboratory. Institutions hastened to dedicate rooms to the installation of multiple tape-desk-equipped booths where students gathered to listen to native speakers modeling the drills of current day's lesson. According to Levis \& Pickering (2004)the application of the speech visualization technology to language learning environment dates back to1960s. Modern language instruction relies more and more on the use of technology in order to convey ideas 
and messages with the help of images, symbols, and sounds. In 2010 James Whiting and Stuart Granoff in a research named 'The Effects of Multimedia Input on Comprehension of a Short Story' quoted: "Vander plank (2009), in a review of research on multimedia in the second-language classroom setting, accepts that new technologies can have a general benefit on comprehension, but is concerned with the challenges and choices facing teachers who want to fully exploit digital technology in the language classroom and laboratory". Listening comprehension is now generally acknowledged as an important facet of language learning; nevertheless, much work remains to be done in both theory and practice (Morley, 2001). Recent advances in computer technology allow the delivery of digital video and audio in the same interface as written text. Although listening is now well recognized as critical dimension of language learning, it still remains one of the least understood processes.

Arguments for listening comprehension began to be voiced in mid-1960s by Rivers who has been "long an advocate for listening comprehension" (Orley, 2001). In 2004, Nobuko Osada from Waseda University in a listening comprehension research mentioned; According to Morley (2001), during the 1980s special attention to listening was incorporated into new instructional frameworks. Many multimedia experts believe that using multimedia technologies in language setting has great advantages (Timucin, 2006). According to Field (2008), our understanding of the conversation might be considerably assisted by facial expressions and visual cues. Most elements are affected on improving listening comprehension as; using video files, audio files, computer applications, etc. While the other three language skills receive direct instructional attention, teachers often expect students to develop their listening skill by osmosis and without help (Mendelssohn, 1984; Oxford, 1993). Audio tales and stories are effective listening materials for children to develop listening comprehension and literacy both in their first and foreign language (Dickinson, 2001; Elley, 1989; Isbell, 2002; Penno, Wilkinson \& Moore, 2002; Raines \& Isbell, 1994; Richards \& Anderson, 2003; Zevenbergenn\&Whitehurst, 2003).

James Whiting and Stuart Granoff from Plymouth State University quoted: "Herron, York, Corrie, and Cole (2006) compared two foreign-language classes: one that used a packaged curriculum with a video component as its primary means of teaching new material, and a second course that relied on a more traditional textbook with supplementary media enrichment". Vander plank (2009), in a review of research on multimedia in the second-language classroom setting, accepts that new technologies can have a general benefit on comprehension, but is concerned with the challenges and choices facing teachers who want to fully exploit digital technology in the language classroom and laboratory. If we want to check the approaches of listening comprehension we can mentionPaul Brett statement which said "the new pedagogical approach to the improving listening comprehension (e.g. Underwood, 1990; Rost, 1990; Anderson and Lynch, 1998) that holds that the learners are interested in development listening by audio and video authentic materials". Studies of motivation and the use of multimedia or interactive video have demonstrated positive effects (Brees, 1996; Watts, 1989). In 2006 Wagner claims the presence of visual support would allow L2 listeners to make more valid inferences, and this could lead to improved L2 listening performance.

In the area of effect of relations between listener and native speaker on listening comprehension we can attend to Listening Education Book (Editor MargareteImhof, Johannes Gutenberg University, Mainz / Germany, 2011)which mentioned Shin (1998) and Wagner (2006) agreed that if L2 listeners have the opportunity to anticipate and see the speakers of the conversation and their relationship before listening, this preview could allow listeners to make more accurate initial hypotheses about speakers' roles and the context of the speaking situation. It also mentioned that According to Field (2008), our understanding of the conversation might be considerably assisted by facial expressions and visual cues. The other 
idea in listening which provided by Wagner (2006) said that researchers are becoming more aware and interested in the role of nonverbal communication in listening comprehension (Baltova, 1994; Buck, 2001; Gruba, 1997).Yang (2006) established a context-aware learning system with the support of multimedia for ubiquitous learning, so students were able to get the information they needed anytime and anywhere. Kalyuga, Chandler, and Sweller (2000) suggested that some multimedia learning software can lead to cognitive overload, which affects learning performance negatively.

According to a research done by Chi-Cheng Chang, Hao Lei and Ju-Shih Tseng, multimedia helps learners learn, but different media presentation modes affect learners' cognitive load differently (Moreno, 2002; Mayer \& Moreno, 2003; Plass, Chun, Mayer \&Leutner, 2003). As the effective way of improving listening comprehension, according to the studies done by Jones and Plass (2002) and Diao, Chandler and Sweller (2007), students learning with double mode (sound and text) outperformed students learning with single mode (sound) and had lower cognitive load. In the presented paper, the research question is scrutinizing of the effect of using audio files on improving listening comprehension.

\section{Method}

\section{Participants}

Statistical sample of the research included thirty four students enrolled twenty sessions in Imam Khomeini high school of Khorramabad program in the study. They are all in pre intermediate level and ranged in age from 16 to 17. The students divided into two groups. Both groups were consisted of seventeen students. To avoid biases and in order to concentrate more on the authenticity of selection process, the name of every student was written in a sheet and seventeen of them were randomly selected as group A and the other seventeen formed group B. These students in this specific level were selected for this study because it is assumed that for clarifying the real effect of audio files on listening comprehension it is better that students with an appropriate background of English language be selected.

\section{Instruments}

For the purpose of identification the level of proficiency of students,25items from 2011 MET-Michigan proficiency test were used.For teaching experimental group, audio files were selected from Tactics for Listening book. For playing audio files two speakers and a Lap Top were used. To teach other skills of language, video projector and power point software was utilized. In order to analyze and compute the obtained scores the SPSSsoftware was used.

\section{Data collection}

In this stage the teacher was involved in teaching experimental group about thirteen minutes in every session. The class was beginning with definition of new words of new lesson and teacher askdstudents the synonym of them. After that the audio file of new reading was played. The teacher was asked some questions about the general information based on heard audio file. The grammar practices were followed by teaching grammar points. The next part was pronunciation practice. All these stages were presented by video projector and listening audio file was played by two speakers with high sound quality. This approach was utilized for control group except playing listening audio file. This type of teaching carried on for three sessions and every session a new lesson was taught. If a student had any problem in understanding the presented materials, the teacher would answer his question and would try to solve the problem. By completion of twenty sessions, the students passed final exam. In this stage the students were listening to an audio file and had to fill out the specified blanks of the script. 
As mentioned before, the students passed final exam. For the purpose of the hypothesis that had proponents that using audio files has no effect on improving listening comprehension, the scores of both groups computed. Then In order to identify the real effect of using audio files, the scores of students compared in SPSS using independent sample T-Test way.

According to the output statistics from the independent sample T-Test, talking about mentioned null hypothesis was easier. In comparison between two tailed significant and the assumed confidence interval which set at $95 \%$, it was understood the supposed hypothesis was rejected. In other words, because the reported significance was minor than significance value, it meant the passedpost test was significant at $.05 \%$.

\section{Group Statistics}

\begin{tabular}{|c|c|c|c|c|}
\hline \multicolumn{4}{|c|}{ Group } & Std. \\
\hline & $\mathrm{S}$ & $\mathrm{N}$ & Mean & Deviation \\
\hline \multirow[t]{2}{*}{ Subjects } & 1 & 17 & 15.12 & 2.497 \\
\hline & 2 & 17 & 13.18 & 2.555 \\
\hline
\end{tabular}

\section{Independent Samples Test}

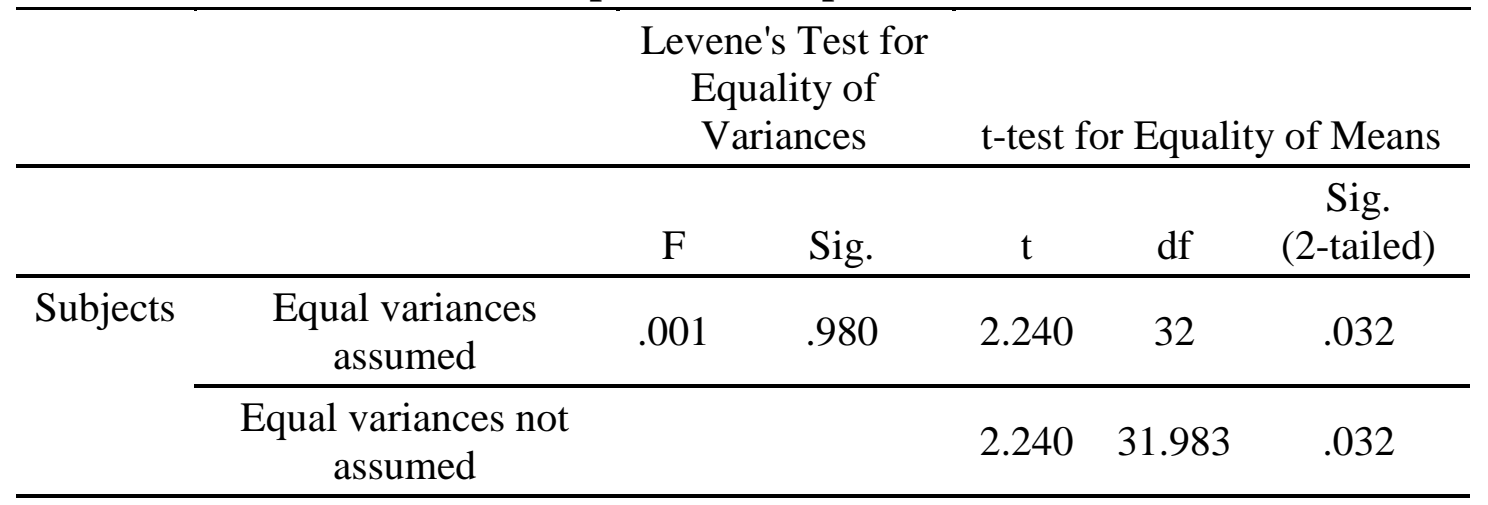

There was, ofcourse, another reason to provethe mentioned rejection. In the analysis of derived statistics, the critical value of $\mathrm{T}$ was minor than the computed observed value of $\mathrm{T}$ at $0.5 \%$ significance in 32 degree of freedom $(2.24>2.02)$.

Discussion

Results from this quasi-experimental study showed that treatment had a significant effect (Sig $<.05)$ on improving listening comprehension. Further investigation of improvement in listening comprehension revealed that using audio files decreased significantly for the treatment group, indicating that their understanding of appropriate listening materials had increased and they had become better able to hear and correctly identify the meaning of what native speakers say.Qualitative data gathered from treatment group participants provided additional insights in other learners' skills. They noted that listening to audio files helped them learn a great deal about English pronunciation, learn to speak English more fluently and correctly, have more homogeneity with native speakers when speaking in public or in situations difficult for them, and feel that people could understand their speech more easily. They also noted that listening to native speaker audio files helped them to have close relation with the culture of second language and to follow the learning process more facilitated. There were some argues in advocating the result of study and against. Sweller (2005) argued that unnecessary or repeated multimedia messages can result in a redundancy effect, which negatively affects learning performance. In the counter of Sweller hypothesis Vander plank (2009), in a review of research on multimedia in the second-language classroom setting, 
accepts that new technologies can have a general benefit on comprehension. By attention to this hypothesis it can be concluded that listening comprehension is affected by audio files. In the other research Shin (1998) and Wagner (2006) agreed that if L2 listeners have the opportunity to anticipate and see the speakers of the conversation and their relationship before listening, this preview could allow listeners to make more accurate initial hypotheses about speakers' roles and the context of the speaking situation.

\section{Limitation}

Based on definition of control variable which is defined as a variable that prevents the possible effects of some elements on the outcome of research; the control variable of present research is gender. In the present research, the examinees were male and were selected during the high school students.

\section{Delimitation}

Although this study was carefully planned and implemented, some important limitations should be noted. First, the period of studying did not let to investigate the effect of audio files completely. This research was accomplished in a high school. It means the background knowledge of students was assumed as intervening variable. So the generalization of findings may not be completely confirmed.

\section{References}

1. MarvaShand-McIntosh, Janice Newton, Kathy Thompson, Teruko (Teri) Akita-Aso, Melissa Beall,MargareteImhof, Barbara Pennington, Josef Walker Beth Walters. (2011). Listening education book. Johannes Gutenberg University, Mainz / Germany

2. Chi-Cheng Chang, Hao Lei and Ju-Shih Tseng. (2011). Media presentation mode, English listening comprehension and cognitive load in ubiquitous learning environments: Modality effect or redundancy effect. National Taiwan Normal University

3. James Whiting, Stuart Granoff. (2010). the Effects of Multimedia Input on Comprehension of a Short Story. Plymouth State University

4. Jie Chi YANGa, Chia Ling CHANGb, Yi Lung LINa, Mei Jen Audrey SHIHa. (2010). A Study of the POS Keyword Caption Effect on Listening Comprehension. aGraduate Institute of Network Learning Technology, National Central University, Taiwan bDepartment of Information Management, National Central University, Taiwan

5. RoyaKhoii, MaleknazAghabeig. (2009).Computer Software and the Improvement of the Elementary EFL Students' Listening Comprehension. Journal of Teaching English as a Foreign Language and Literature

6. Mark W. Tanner, Melissa M. Landon. (2009). the effects of computer-assisted pronunciation readings on esl learners' use of pausing, stress, intonation, and overall comprehensibility. Brigham Young University

7. Londe, Zsuzsa C. (2009). The Effects of Video Media in English as a Second Language Listening Comprehension Tests.Issues in Applied Linguistics, 17(1)

8. Dolores RamírezVerdugo , Isabel Alonso Belmonte. (2007). using digital stories to improve listening comprehension with spanish young learners of English. Universidad Autónoma de Madrid (Spain) 
9. Mónica S. Cárdenas-Claros and Paul A. Gruba. (2007). Help options in computer based listening activities: Learning scaffolds or barriers.School of Languages and Linguistics The University of Melbourne

10. Nobuko Osada.(2004). Listening comprehension research: a brief review of the past thirty years. Waseda University

11. Petra PoelmansgeborenteHeusden. (2003). Developing second-language listening comprehension: Effects of training lower-order skills versus higher-order strategy. Utrecht, The Netherlands: LOT press

12. ShaBalizet, Dave Treder, Cynthia G. Parshall. (1999). the development of an audio computer-based classroom test of ESL listening skills. University of south Florida

13. Gruba Paul. (1997). the role of video media in listening assessment. The University of Melbourne, Melbourne, Victoria, Australia

14. Brett Paul. (1997).A comparative study of the effects of the use of multimedia on listening comprehension. School of Languages and European Studies, University of Wolverhampton, Wolverhampton, U.K

15. Carla Meskill. (1996). Listening Skills Development through Multimedia. Department of Educational Theory and Practice University at Albany, State University of New York Albany, NY 12222, USA

16. MET sample Items. (2011). Michigan University 